\title{
Deconstruction and the Transformation of Husserlian Phenomenology
}

Chung Chin- Yi

\section{Husserl's Project}

$\mathrm{I}$

$\mathrm{n}$ this paper I will examine Husserl's attempt to establish a ground for science with the so called transcendental reduction. This will entail both well as a careful analysis of Husserl's account of his methodology. I will then examine how Derrida's reading, which affirms the phenomenological project in many of its essential aspects, begins to signal a subtle yet ultimately radical disagreement. This disagreement will have lasting implications for our understanding of the possibilities designated by the transcendental method in Husserl's thinking.

Husserl, in attempting to bracket the natural world through his transcendental reduction, was seeking an absolute foundation in which to ground science. This a priori grounding would establish science in a solid and unshakeable foundation that subsequently resolved all the crises of foundations in the European sciences. Husserl's positing of this a priori ground was his solution to relativism by grounding science in a solidfoundation. Husserl seeks to overcome psychologism and relativism through establishing an a priori and absolute foundation for science. As Husserl puts it on establishing an a priori foundation for science:

This implies that in and through the establishment of the a priori the subjective method of this establishing is itself made transparent, and that for the a priori disciplines which are founded within phenomenology (for example, as mathematical sciences) there can be no 'paradoxes' and no 'crises of foundations'. The consequence that arises (from all this) with reference to the a priori sciences that have come into being historically and in transcendental naiveté is that only a radical, phenomenological 


\section{DECONSTRUCTION AND HUSSERLIAN PHENOMENOLOGY}

grounding can transform them into true, methodical, fully justifying sciences. ${ }^{1}$

Husserl thus seeks a science that grounds itself radically as an a priori science, its justification and method would lie in its absolute ideal foundation which would resolve problems that involved crises of foundations and logical paradox. This also included problems of subjectivism- in positing the a priori as the unshakeable ground of phenomenology Husserl sought a method in which to objectify the sciences and find a radical foundation upon which the unquestionable certainty and objectivity of the sciences would be founded through the transcendental reduction. As Husserl puts it on the necessity of the transcendental reduction:

Phenomenological psychology in this manner undoubtedly must be established as an 'eidetic phenomenology'; it is then exclusively directed toward the invariant essential forms. For instance the phenomenology of perception of bodies will not be (simply) a report on the factually occurring perceptions or those to be expected; rather it will be the presentation of invariant structural systems without which perception of a body and synthetically concordant multiplicity of perceptions of one and the same body as such would be unthinkable. If the phenomenological reduction contrived a means of access to the phenomenon of real and also potential inner experience, the method founded in it of 'eidetic reduction' provides the means of access to the invariant essential structures of the total sphere of pure mental process. $^{2}$

Transcendental reduction is a method at which one arrives at apodictic certainty-at the essences which form the a priori conditions upon which empirical phenomenology is premised. Phenomenology is eidetic phenomenology - it seeks to arrive at the genetic foundations of thought, as Husserl puts it- moves phenomenology from static to genetic-in arriving at the pure, invariant, essential forms which synthesize perceptions into coherent unities and without which perception would be impossible. Husserl sought, through the eidetic reduction, to arrive at the essential structures of the pure mental process; in this sense the transcendental reduction is a purifying process of bracketing everything contingent, empirical and relative to arrive at the absolute and a priori foundations that structure mental processes.

${ }^{1}$ Edmund Husserl, Shorter Works, ed. by Peter Mccormick and Frederick A. Elliston (Indiana: Univesityof Notre Dame Press, 1981), 32.

2 Ibid., 25. 
This paper will seek to examine the conditions of possibility for establishing Husserl's absolute ground of certainty in its a priori formulation by moving from establishing the need for the transcendental reduction, which we have just seen to be the consequence of Husserl's quest to ground science with an absolute and unshakeable foundation; and then examining Derrida's account of the conditions for arriving at apodictic certainty through its foundational condition of possibility—the trace and différance.

\section{Derrida's Reading of the Absolute}

In Derrida's reading, the Absolute is constituted by repetition and representation and not presentation, which has never existed in the first place. This Absolute is the point of origin that grounds presence in logocentric discources. The absolute has to be re-activated through time and history by the iteration of the noema and the repetition of presence in absence, being in non-being; that bifurcates the a priori. This absolute is always deferred and delayed, spatially and temporally, communicated to us through the passage of différance. For instance Derrida states in Introduction to Origin of Geometry that:

Here, on the contrary, the here and now of the 'first time' is institutive and creative. Is this experience, unique of its kind, not a singular fact-one for which we should not be able to substitute another fact as an example in order to decipher its essence?

Is this to say that this inseparability of fact and sense in the oneness of an instituting act precludes access for phenomenology to all history and to the pure eidos of a forever submerged origin?

Not at all. The indissociability itself has a rigorously determinable phenomenological sense. The imaginary variation of static phenomenology simply supposed a type of reduction whose style will have to be renewed in a historical phenomenology. The eidetic aspect of this reduction was the iteration of a noema: since the eidos is constituted and objective, the series of acts which intended it could not but indefinitely restore the ideal identity of sense which was not obscured by any historical opacity, and it would only be a question of clarifying, isolating, and determining its evidence, invariance, and objective independence. The historical reduction, which also operated by variation, will be reactivating and noetic. Instead of repeating the constituted sense of an ideal object, one will have to reawaken the dependence of sense with respect to an inaugural and institutive act concealed under secondary passivities and infinite sedimentations - a primordial act which created the 


\section{DECONSTRUCTION AND HUSSERLIAN PHENOMENOLOGY}

object whose eidos is determined by the iterative reduction. Here again we are going to see that there is no simple response to the question of the priority of one reduction over another. ${ }^{3}$

Derrida shows that the relation between the eidetic reduction and the absolute origin is one of repetition-the reduction is the iteration of the noema, it re-awakens the dependence of sense with respect to the institutive and creative act of the absolute origin which, far from being submerged and lost, is re-activated through the reduction through repetition with a difference in the present; thus de-sedimenting the concealed origin of the past and reactivating it in the present and future. The Absolute origin of the past which was instituted creatively 'for the first time' by the first geometers is thus reactivated through the reduction through the iteration of the noema, or the repetition of the Absolute with a difference in the present. This origin is produced only retrospectively through the act of repetition, signalling to a presence that never existed. Repetition produces the subsequent division into transcendental and empirical retrospectively signalling to a presence that must have existed but was never there through the differentiating movement of the trace.

The Absolute, or its myth, is thus constituted by this re-activating iteration of the noema, or repetition with a difference in the present and future through the reduction. Further Derrida states that:

The impossibility of resting in the simple maintenance (nowness) of a Living Present, the sole and absolutely absolute origin of the De Facto and the De Jure, of Being and Sense, but always other in its self-identity: the inability to live enclosed in the innocent undividedness (indivision) of the primordial Absolute, because the Absolute is present only in being deferred-delayed (differant) without respite, this impotence and this impossibility are given in a primordial and pure consciousness of Difference. Such a consciousness, with its strange style of unity, must be restored to its own light. Without such a consciousness, without its own proper dehiscence, nothing would appear.

The primordial Difference of the absolute Origin, which can and indefinitely must both retain and announce its pure concrete form with a priori security, i.e. the beyond or the this-side which gives sense to all empirical genius and factual profusion, that is perhaps what has always been said under the concept of

${ }^{3}$ Jacques Derrida, Edmund Husserl's 'Origin of Geometry': An Introduction, trans. by John P. Leavey, Jr. (New York; Hassocks: Harvester Press; Hays, 1978), 47-48. 


\section{CHIN-YI}

'transcendental' through the enigmatic history of its displacements. Difference would be transcendental. The pure and interminable disquietude of thought striving to 'reduce' Difference by going beyond factual infinity toward the disquietude would be transcendental. And Thought's pure certainty would be transcendental, since it can look forward to the already announced Telos only by advancing (or being in advance of the Origin that indefinitely reserves itself. Such a certainty never had to learn that Thought would always be to come.

The strange procession of a 'Ruckfrage' is the movement sketched in The Origin of Geometry, whereby this piece of writing also holds, as Husserl says, an 'exemplary significance. ${ }^{4}$

Derrida discusses the conditions of possibility of the Absolute-it is always relayed spatially and temporally through the passage of différance, deferred and delayed in order to be communicated. As Derrida puts it earlier, the Absolute is passage - the Absolute is re-activated through the iteration of the noema, of what Derrida calls the movement and the procession of the 'Ruckfrage.' It is the possibility of the iteration of the noema, and the reactivation of the Absolute origin that ensures it transmission through time and history from past to future, as Derrida puts it 'Thought would always be to come'. ${ }^{5}$ The Absolute is thus never present to itself or undivided in the Living Present, it is always delay, and thus the Living Present is always co-existent with the past and the future, or the not-now. Presence is thus aligned with non-presence in the forms of past and future in order to be perpetuated, the Absolute is constituted through its repetition and deferral through space and time in order to be communicated. As Derrida puts it, pure thought is always delay. The Absolute origin, or its myth, thus has to be re-activated through its iteration and conveyed through the passage of différance in order to perpetuate itself through space and time. Repetition produces the Absolute origin retrospectively through division into the transcendental and empirical reproducing a presence which was never there. The Absolute, or the transcendental, is thus really différance, or delay and deferral in its passage through time and history to be perpetuated from past to future. The Absolute always differs from itself in its repetition with a difference or différance, without this difference or deferral through space and time, nothing would appear to consciousness.

${ }^{4}$ Ibid., 153.

${ }^{5}$ Ibid. 


\section{DECONSTRUCTION AND HUSSERLIAN PHENOMENOLOGY}

\section{Derrida's 'Disagreement' with Husserl}

Derrida's disagreement with Husserl, in Speech and Phenomena and Introduction to Origin of Geometry, takes the form of a non-synonymous substitution. The non-synonymous substitutions for Derrida in the Différance essay are terms such as pharmakon, supplement, arche-writing, trace, protowriting, reserve, things which mean different things in different contexts but perform the same function in Derrida's work of naming the aporia that takes place in different contexts where there is a inescapable haunting of presence by non-presence and the greater structure that the terms belong to. In Derrida's work, these aporias or displacements are produced as a 'chain' of 'non-synonymous substitutions' in which difference defers and differentiates itself differently in accordance with the (contextual situation in which its movement is solicited: in reading Plato, for instance, Derrida finds the trace of difference inscribed in the thought of writing as pharmakon ${ }^{6}$ (meaning both 'poison' and 'cure'); in Rosseau, it appears as 'the supplement' (meaning both 'the missing piece and the extra piece'); in Mallarme, as 'the hymen' 7 (indicating both 'inside and outside,' 'virginity and consumation'; and even when he explicates différance under its 'own' name, this explication is carried out only through its dissimulation into other names ('reserve,'trace,' 'archi-trace,' and 'archi-writing' etc), each of which may stand in for this movement in a given context, but none of which- including 'différance' itself- may claim authority over the open system in which it plays and through which its effects are produced and dispersed. ${ }^{8}$

Derrida's reading affirms that it is différance and repetition that constitutes the Absolute rather than the transcendental. Such a reading accounts for the perpetuation of the Absolute through time and history, as the Absolute has to be re-activated through its iteration in the present and future in order to sustain itself through space and time. This delay and deferral through space and time is the passage of différance which the Absolute, or its myth, has to pass through in order to be communicated from its institution in the past to the present and future. This absolute origin is only produced retrospectively through the differentiating movement of difference and the trace. Derrida's reading develops and affirms in Hegelian terms rather than being a contradiction or disagreement. Contradiction and disagreement, on Hegelian terms, should be replaced with phrases like process and evolution or process. Reading from Hegel:

The more the current opinion views the opposition between true and false as rigid, the more it expects that every given philosophical system should be either

\footnotetext{
${ }^{6}$ Jacques Derrida, Dissemination, trans. by Barbara Johnson (Chicago; London: Athlone Press; University of Chicago Press, 1981), 115.

${ }^{7}$ Ibid., 217.

8 Jacques Derrida, Margins of Philosophy, trans. by Alan Bass (Brighton; Chicago: University of Chicago Press; Harvester Press, 1982), 12-13.
} 
endorsed or contradicted, and takes every explanation of such a system to be only the one or the other. It does not conceive the diversity of philosophical systems as the progressive development of truth, it only sees contradiction in that diversity. The bud disappears in the eruption of the flower, so one could say that the flower contradicts the bud. In a similar way, the fruit declares the flower to be the plant's false existence, and steps forward in its place as the plant's truth. These forms are not only distinct; they reject one another as mutually exclusive. At the same time, their fluid nature makes them into moments of an organic unity, in which they not only do not struggle with each other, but one is as necessary as the other; and only this equal necessity constitutes the life of the whole. ${ }^{9}$

The widely held view of philosophy holds that two contradictory claims, or philosophical doctrines, are mutually exclusive. Only one of them can be true, while the other is a falsehood. Hegel proposes a different view according to which conflicting philosophical doctrines are all dynamic constituents or 'moments' of Truth, every moment emphasizes a single, partial aspect of the whole truth. Truth is thus organic and evolutionary, each 'moment' of truth is a progressive development towards the whole Truth or Absolute. Each 'moment' of truth thus represents a constituent truth on the path to the growth and development of the Absolute.

Contradiction and disagreement as the relationship between philosophers needs to be reformulated as development towards the synthesis of progressive truth because it is a more accurate description of what actually takes place when one philosopher 'disagrees' with another, philosophers essentially do not disprove the theory or systems of each other as the formal qualities of the expression of the Absolute is sustained. The Absolute only takes on different forms as each philosopher evolves the relationship between the transcendental and empirical into a different shape but essentially these are repetitions of the same fundamental axioms and truths.

Does the existing formulation of disagreement accurately capture what is at stake when a so called disagreement arises between philosophers? As Hegel has it, disagreement translates only half of the story, as the formal qualities of the alternative philosophies developed, such as transcendental empirical difference remains the same rather than diverge. Rather each philosopher develops and progressively evolves the notion of the relationship between the transcendental and empirical by giving these a new shape and form and evolving it into new systems which essentially share the same principle of the Absolute. Is there truly a disagreement between philosophers

9 Georg Wilhelm Friedrich Hegel, Hegel's Preface to the Phenomenology of Spirit, trans. Yirmiyahu Yovel (Princeton: Princeton University Press, 2005), 65-67. 


\section{DECONSTRUCTION AND HUSSERLIAN PHENOMENOLOGY}

when the formal qualities of their formulation remain the same, in the form of transcendental empirical difference? The differences, or disagreements between philosophers, are on the level of form and appearance rather than substance. The grounding principle of the Absolute remains the same. No difference exists between the philosophers as they are a repetition of the principle of the Absolute. No disagreement or contradiction thus arises between the philosophers.

Hence does Derrida's reformulation of transcendental-empirical difference in his notions of différance and trace contradict or develop the preceding philosophers? In many senses, Derrida affirms and develops philosophy by discovering that the fundamental relationship between the transcendental and empirical is one of repetition with a difference as a priori difference produces subsequently the illusory distinction of the transcendental and empirical in theatrical production through the differentiating movement of différance and the trace. Derrida also discovers that the difference that separates the transcendental and empirical is a difference which is nothing. This formulation of the transcendental and empirical does not contradict or disagree with previous arguments of the philosophers but develop and affirm it by discovering its conditions of possibility-différance and trace are the conditions of possibility for the formulation of the transcendental and empirical. These transcendental and empirical are not separate and reified entities ontologically but repetitions with a difference, or traces. The difference which is nothing is presupposed by phenomenology from the beginning in its being the condition of possibility for the phenomenological reduction. Derrida discovers that the condition of possibility for a priori difference is that it is a difference which translates into nothing because it distinguishes nothing and separates nothing. Death thus lies at the heart of life and the Living Present and constitutes it, produces it through the differentiating trace out of which presence and absence, being and non-being arise. This is the aporia of phenomenology_death constitutes life. Derrida also examines the aporia that the transcendental-empirical distinction simply does not allow the phenomenological reduction to take place, and resolves these contradictions in Husserl's phenomenology through his positing of the quasi-transcendental, or the economy and repetition of the transcendental in the empirical. Critics of Derrida have been mistaken in classifying Derrida as an empiricist and a nihilist. Differance and trace are not empirical concepts. Differance and trace are an a priori difference out of which subsequent differentiations and determinations of the illusion of transcendental empirical difference arise. Derrida's post-phenomenology addresses the fundamental problems of phenomenalism and solipsism that a sole transcendental account of genesis leads phenomenology to.

The transcendental and empirical differ only in name and are produced theatrically as distinct through the movement of différance and the trace. The transcendental and empirical, along with the illusion that they are distinct, arises out of the movement of iterability, which re-activates the noema and perpetuates it through time and history. Derrida's arguments are a 
development towards the Absolute by discovering the a priori conditions of possibility for the transcendental empirical distinction as repetition with a difference and the a priori difference, or différance, as a difference which translates as nothing. Hence does Derrida contradict or affirm and develop philosophy? I incline towards the latter view as Derrida examines the conditions of possibility for the (re)production of the Absolute, which is formed retrospectively through the act of repetition which signals to an origin which must have been but was never there, through the movement of iterability and difference.

Derrida's non-synonymous substitution for Husserl's thought does not contradict but develop his phenomenology by examining the very conditions of possibility for Husserl's transcendental idealism, positing these as différance and iterability. ${ }^{10}$ Through his non-synonymous substitution of différance, Derrida discovers that a priori difference, or the difference that translates into a nothing that separates the transcendental and empirical, is the condition of possibility for phenomenology. Paradoxically thus, Derrida's disagreement with Husserl does not destroy but affirm and is a meta-phenomenological examination of the conditions of possibility for Husserl's project. Husserl posits the conditions of possibility for epistemic knowledge as the a priori, or the transcendental and the noema which constitutes the real by structuring perception into coherent unities, for example giving discrete impressions the properties of space and time. Yet this account of transcendental constitution says nothing about the method in which metaphysics is perpetuated and sustains itself through the passage of time and history. What is the very condition of possibility for transcendental constitution?

Derrida traces the genesis of the transcendental to the trace, or the nothing that separates the transcendental and empirical, out of which further differentiating traces arise. The trace, or différance, the nothing between the transcendental and empirical, out of which the differentiation which produces presence and absence, being and nothing arises, is the a priori difference and condition which sustains metaphysics rather than solely the transcendental. A transcendental account of constitution says nothing about genesis and metaphysical production and perpetuation. How does the Absolute get transmitted through history? The transcendental noema has to be iterated and conveyed through différance in order to be communicated. A priori difference, or différance, is the condition of possibility for transcendental genesis and metaphysical production. The transcendental is produced theatrically as separate from the empirical through the distinguishing movement of différance and the trace. Yet this a priori difference, or différance, is a difference that is nothing and distinguishes nothing as transcendental and empirical are but historical names derived from metaphysics. The transcendental and empirical are the illusory distinctions and theatrical productions of metaphysics, only differing in name as repetitions

10 Jacques Derrida, Speech and Phenomena, and Other Essays on Husserl's Theory of Signs, trans. by David B. Allison (Evanston: Northwestern University Press, 1973), 57. 


\section{DECONSTRUCTION AND HUSSERLIAN PHENOMENOLOGY}

with a difference, but each repetition differs and separates itself from the original mark, produced as the trace.

Derrida questions the idea that the isolation of the transcendental through the act of phenomenological reduction results in accounting for the conditions of possibility for knowledge as the absolute a priori. This reduction negates the movement of iterability, or repetition with a difference from the original mark, which is the mode of production for metaphysics. The transcendental is distinguished from the empirical only as an illusion through the reproductive movement of the trace, and hence reduction nullifies this movement of repetition and difference, or différance, which is the condition of possibility for metaphysics. The phenomenological reduction negates the a priori difference, or différance, which is necessary to account for how metaphysics sustains itself. The transcendental is only produced separately from the empirical through the illusion of a distinction that occurs through the movement of différance, hence expression without indication, signified without signifier, ideal without real becomes an incoherent postulate. Derrida does not dispute the necessity of the phenomenological reduction to arrive at the true conditions of knowledge, but argues that it reverses or annuls the movement of iterability. Iterability is the repetition which constitutes ideality and enables it to come into being. It is iterability and repetition that constitutes ideality rather than the transcendental as the ideal has to differ from itself through repetition to come into being. As argued by Derrida, the reduction is a re-activation of the noema, rather than its negation. The reduction is a theatrical production and illusion that produces the transcendental as separate from the empirical, hence positing the transcendental without the empirical as its mediation becomes an incoherent postulate. The problem with a transcendental account of constitution is that it does not account for genesis and metaphysical production and perpetuation. Derrida's meta-phenomenology, with his account of différance and iterability as the conditions of possibility for phenomenology, gives such an account. Iterability is the principle by which the reduction is negated and enabled-it is precisely what makes the transcendental, empirical and the division between them deconstructible as it is what allows its own negation and performs its own repetition. It is the very principle of iterability in its reversibility of the reduction and its simultaneous enabling of it that makes the transcendental and empirical deconstructible.

This brings us to an area of contention that Derrida has with Husserl. Husserl insists on the rigid distinction between the transcendental and the empirical in order to institute his transcendental idealism as the condition of possibility for knowledge. Yet according to Derrida, this distinction is incoherent as the transcendental is produced in an illusion as separate from the empirical only through the differentiating movement of the trace, and through the movement of iterability. The transcendental is nothing outside its theatrical production through the empirical in which it displays itself; hence while Husserl posits the distinction between transcendental and empirical as ontological and substantive, Derrida will show that the phenomenological reduction would not be able to take place if this were so. Rather, Derrida 


\section{C. $\mathrm{CHIN}-\mathrm{YI}$}

demonstrates that the difference between the transcendental and empirical is a difference which translates as nothing; it is a difference which is paradoxically a sameness because it separates nothing and distinguishes nothing. It is precisely différance which translates as nothing separating the transcendental and empirical which enables the phenomenological reduction, were the difference ontological or substantial the phenomenological reduction would not be able to take place. Derrida thus examines the fundamental aporia of Husserl's metaphysics - the fundamental and rigid distinction which Husserl posits as ontological and substantive would not allow the phenomenological reduction to take place if it truly held. Derrida's account of the difference which translates as nothing and distinguishes nothing, and is paradoxically not a difference but a sameness, accounts for the very conditions of possibility of the phenomenological reduction and transcendental genesis.

\section{Différance and Iterability}

Traditionally the transcendental has been posited as the sole source and origin of the empirical. Yet this says nothing about the dynamic constitution between the transcendental and empirical which enables their relationship. It does not account for the movement of the a priori difference across these metaphysical categories, or the trace, which enables transcendental-empirical constitution. Derrida traces back the condition of possibility for the transcendental-empirical relation to différance, or the a priori difference and nothing, spacing, or interval which separates the transcendental and empirical. The a priori difference contains an aporia: it is paradoxically a difference which is a sameness because it separates nothing. This difference which translates as a nothing enables the mediation of the transcendental in the empirical and the phenomenological reduction, were this difference ontological or substantial the phenomenological reduction would not be able to take place and the transcendental would not be able to be mediated in the empirical. Husserl's distinction between the transcendental and empirical as a substantive and ontological division thus becomes an incoherent distinction because of the above reasons. As Derrida argues, transcendental-empirical difference, or différance, is more functional than substantial.

This trace of repeatable traces produces both the transcendental and empirical in the reproductive movement of iterability. The a priori difference between the transcendental and empirical which translates as nothing, or différance, sustains metaphysics through maintaining their dynamic constitution as iterability. Différance translates as the reproduction of this nothing, or a priori difference that separates the transcendental and empirical, which enables metaphysical production and bifurcates the a priori between presence and non-presence. In place of the transcendental as sole constitutor of the empirical thus, Derrida argues that a priori difference, or différance, sustains metaphysical production. Objective knowledge or science is thus able to conceive the life-world through mediation of the transcendental in the empirical, or différance and iterability, rather than through the sole sustenance 


\section{DECONSTRUCTION AND HUSSERLIAN PHENOMENOLOGY}

of the transcendental. Rather the relation of repetition between the transcendental and empirical, or iterability, sustains metaphysics and allows metaphysical production to take place. The transcendental comes into life in the world only through an illusionary distinction through the movement of the trace, as a difference from itself as the original mark. This was previously discussed as the re-activation of the noema through its iteration.

Derrida describes the difference between the transcendental and empirical as a difference which is nothing:

For the domain of pure psychological experience incorporates the total domain of what Husserl calls transcendental experience. Yet despite this perfect incorporation, a radical difference remains, one having nothing in common with any other difference, a difference in fact distinguishing nothing, a difference separating no state, no experience, no determined signification- but a difference which, without altering anything, changes all the signs, and in which aloe the possibility of a transcendental question is contained. That is to say, freedom itself. A fundamental difference, thus, without which no other difference in the world would either make sense or have the chance to appear as such. Without the possibility and the recognition of such a duplication (Verdoppelung), whose rigour tolerates no duplicity, without this invisible distance held out between the two acts of the epoche, transcendental phenomenology would be destroyed in its root. ${ }^{11}$

Above we see Derrida's accounting for a priori difference, différance. Derrida posits différance as the primordial difference between the transcendental and the empirical which is nothing, it translates into the fundamental spacing, delay or deferral of meaning which becomes the trace of repeatable traces giving rise to the differentiating movement of presence and absence, transcendental and empirical, philosophy and non-philosophy through the movement of différance and iterability. This difference distinguishes nothing, separates nothing, but translates into the primordial trace or difference out of which all subsequent traces and differentiations producing transcendental and empirical arise. As Derrida argues, this a priori difference, or trace, is the condition of possibility of both the transcendental and empirical as it translates into the reproductive movement or duplication (Verdoppelung) of this trace or nothing distinguishing the transcendental and empirical which gives rise to metaphysical production through the movement of iterability, or the repetition of the transcendental in the empirical with a difference. The condition of possibility for phenomenology hence becomes this perpetuating

${ }^{11}$ Ibid., 11. 
trace or a priori difference which is nothing, a difference from the original mark as repetition of the same. This nothing which distinguishes the transcendental and empirical becomes what enables the phenomenological reduction:

This nothing that distinguishes the parallels, this nothing without which precisely no explication, that is, no language, could be freely developed in the service of truth without being deformed by some real contact, this nothing without which no transcendental (that is, philosophical) question could be opened, this nothing arises, so to speak, when the totality of the world is neutralized in its existence and is reduced to its phenomenal being. This operation is that of the transcendental reduction; it may in no case be that of the psychophenomenological reduction ${ }^{12}$.

The nothing which distinguishes the transcendental and the empirical translates into the trace, or différance, which becomes their a priori condition of philosophy that arises out of the transcendental reduction. It is the possibility that the transcendental can be reduced to the empirical or phenomenal, or the nothing that separates them, which enables the reproductive movement of both the transcendental and empirical in metaphysical production through iterability. The transcendental does not exist outside its illusory reproduction through the empirical. A priori difference which translates as the nothing separating the transcendental and empirical enables the phenomenological reduction. Iterability translates as the repetition of the transcendental in the empirical as a difference from the original mark which is, as Derrida argues, paradoxically a difference which is nothing, and separates nothing.

Différance translates as a priori difference, or transcendental difference, yet its distinction contains an aporia because it is a difference which translates as nothing or separates nothing; because the transcendental does not exist outside the empirical, the ideal does not exist outside history and the real, the transcendental ego does not exist outside the empirical ego, just as the transcendental is nothing outside the history and sedimentations in which it displays itself. Différance, as Derrida states, is a sameness which is not identical. This is the aporia of metaphysics - the difference between the transcendental and empirical translates paradoxically into a sameness, because the transcendental is the empirical, and cannot exist outside of it as iterability or repetition with a difference from the original mark, what we discussed in the earlier chapter as re-activation of the noema through iteration.

12 Ibid., 12. 


\section{DECONSTRUCTION AND HUSSERLIAN PHENOMENOLOGY}

\section{Husserl's Logocentrism}

Husserl maintains a rigid distinction between the transcendental and empirical in the text that consolidated his phenomenology as a transcendental idealism, namely, Ideas I. For instance, in his beginning chapter he institutes the separation of fact and essence, the real and the irreal, and maintains the principle of principles in his phenomenology, that every intuition is a source of authority for knowledge, that whatever presents itself in 'intuition' in primordial form is simply to be accepted as it gives itself out to be, though only within the limits in which it then presents itself. ${ }^{13}$ In other words, Husserl privileges intuition or the ideal given-ness of an object as its reality. (This move is seen by Derrida to privilege presence as what is given is presented entirely to itself, hence this makes the ideal absolute). Derrida discusses logocentrism in Speech and Phenomena:

In this sense, within the metaphysics of presence, within philosophy as knowledge of the presence of the object, as the being-before-oneself of knowledge in consciousness, we believe, quite simply and literally, in absolute knowledge as the closure if not the end of history. And we believe that such a closure has taken place. The history of being as presence, as self-presence in absolute knowledge, as consciousness of self in the infinity or parousia - this history is closed. The history of presence is closed, for 'history' has never meant anything but the presentation (Gegenwartigung) of Being, the production and collection of beings in presence, as knowledge and mastery. Since absolute self-presence in consciousness is the infinite vocation of full presence, the achievement of absolute knowledge is the end of the infinite, which could only be the unity of the concept, logos, and consciousness in a voice without différance. The history of metaphysics therefore can be expressed as the unfolding of the structure or schema of an absolute willto-hear-oneself speak. This history is closed when this infinite absolute appears to itself as its own death. A voice without différance, a voice without writing, is at once absolutely alive and absolutely dead. ${ }^{14}$

In the above passage Derrida discusses the conditions of possibility of logocentrism with the discovery of différance. Logocentrism privileges presence as the objective presentation of intuition given entirely to itself, which

\footnotetext{
13 Edmund Husserl, Ideas Pertaining to a Pure Phenomenology and to a Phenomenological Philosophy, First Book, trans. by F. Kersten (Dordrecht: Kluwer, 1983), 92.

${ }^{14}$ Derrida, Speech and Phenomena, 102.
} 
Husserl privileges in solitary mental life as expressive signs over indication. Intuition as absolute, present, objective and given to itself (being as presencethe presentation (Gegenwartigung) of being), amounts to what Derrida posits as Husserl's logocentrism. The closure of metaphysics and the end of historymetaphysics as an absolute idealism which fails to acknowledge the différance, or the difference between transcendental and empirical, which constitutes metaphysics-becomes what Derrida wishes to save phenomenology from with his post-phenomenology and quasi-transcendental. Derrida shows that the trace and death lie at the heart of presence and embody its condition of possibility. Différance translates into the contamination of the transcendental and empirical, or the interaction between them in the reproductive movement of iterability.

Différance maintains the illusion that the transcendental and empirical are separate when it is paradoxically a difference that is nothing, that separates nothing because the transcendental translates into the empirical. Metaphysics becomes the will-to-hear-oneself speak-as intuition given entirely to itself in expression or solitary mental life in full presence. Such a privileging of presence fails to acknowledge différance as its source - or an acknowledgement of the economy and repetition of the transcendental in the empirical which constitutes metaphysics.

Derrida wishes to argue for a metaphysics that acknowledges différance as its grounds of possibility and source, or the economy and repetition of the transcendental in the empirical which enables metaphysics. Derrida argues for a metaphysics that acknowledges the quasi-transcendental, which is the spacing between the transcendental and the empirical that enables metaphysics in the movement of différance or iterability. In this way Derrida wishes to save metaphysics from its absolute closure and death- by bringing it to acknowledge what it had repressed- différance and the quasi-transcendental, as its condition of possibility. Derrida pronounces not so much the end of logocentrism as what makes it possible- différance and iterability which produces metaphysics through the fundamental relation of repetition with a difference. The transcendental distinction from the empirical is an illusion, differing from itself through repetition with a difference, which in effect distinguishes nothing and separates nothing.

\section{Thing and Space}

Husserl sets down the conditions of possibility of perception in Thing and Space by formulating these in terms of pre-empirical constitutive functions of space and time. Objects are constituted and given in terms of these ideal structures which are apprehended and apperceived, which the mind imposes and processes manifold perceptions, or pure empirical datum, to form continuous unities. This sets down the ideal as the condition of possibility for the empirical, as Husserl argues, objects are intended, intentionality constitutes the empirical in terms of the ideal. The problem with such a formulation is that it sets a rigid dichotomy and sets apart the ideal and the empirical, 


\section{DECONSTRUCTION AND HUSSERLIAN PHENOMENOLOGY}

resulting in an aporia of non-correlation and distinctness between the transcendental and the empirical. The phenomenological reduction which Husserl repeatedly institutes in order to arrive at the conditions of knowledge, namely space and time, also results in an aporia by nullifying the phenomenon of différance and iterability, which, according to Derrida, translate as the condition of possibility of the ideal.

As discussed earlier, iterability becomes a more reasonable account of the way in which metaphysics functions and more consistent with the doctrine of intentionality than the reduction or the transcendental epoche. Différance constitutes ideality through repetition, or iterability, and ideality is only made possible by its iterability or repeatability. Intentionality implies that the ideal and empirical are mutually implicated and the reduction that is performed in order to arrive at pre-empirical forms of space and time thus negates the phenomenon of iterability which translates into the condition of possibility of the ideal.

Husserl further distinguishes real and reell, or transcendent and immanent perception. Husserl posits immanent perception as absolute and the condition of possibility of transcendent perception. This leads to a logocentrism which forgets its origin as différance, also as discussed earlier, it is counter-intuitive that immanent perception is the sole constitutor of transcendent perception rather than the trace, which is the a priori difference which is the very condition of possibility for transcendental genesis. Perception, as argued by Derrida, finds its condition of possibility in the trace, or différance, and the repetition of the transcendental in the empirical. Immanent perception iterates transcendent perception and hence is its mediation, rather than solely determined by transcendent and pre-empirical intuition. The transcendental is produced as separate and distinct from the empirical only through the illusory movement of différance, it is the iterability that produces the illusion of the transcendental and empirical as separate through the distinguishing movement of the trace, or the production of its difference from the original mark that sustains metaphysics.

The reduction repeatedly performed by Husserl to arrive at the pure conditions of knowledge, the immanent or pre-empirical that unites discrete phenomena, manifold perception, or dead matter into continuous unities of

objects, thus lands phenomenology in an aporia by nullifying the movement of différance and iterability which are the true conditions of possibility for ideality. The reduction paradoxically is a repetition and iteration of the noema rather than the isolation of the transcendental through negating the empirical. The reduction can only be performed through this repetition or iteration of the noema, and thus to define transcendental without empirical lands phenomenology in an aporia. The transcendental is only produced as separate from the empirical as an illusion, through the retrospective movement of the trace, thus the phenomenological reduction in effect nullifies phenomenology's conditions of possibility by negating the movement of iterability. This aporia becomes resolved by Derrida's account of the quasi-transcendental, which posits the relation of iterability or repetition with a difference which produces 
the illusion that transcendental and empirical are distinct when they are the same.

As Derrida has argued in Of Grammatology, every signified is already in the position of signifier, and the signified only exists through its mediation as the signifier to come into being, Husserl's rigid distinction between transcendent and immanent perception will thus be shown to be in this sense, problematic. This problematization however will not be taken for granted. It will be asked if this problematization is necessary to arrive at the conditions of possibility for knowledge and if the account of the transcendental in phenomenology or the quasi-transcendental in post-phenomenology provides a more convincing account of a theory of knowledge. It will be asked if Derrida's positing of the quasi-transcendental saves phenomenology by positing the dynamic relation between them as différance and repetition, as the ideal has to differ from itself as the original mark through repetition with a difference to be instantiated. This enables phenomenology to move from static to genetic by naming the conditions of possibility for transcendental genesis. These are différance and the space. The transcendental is only formed retrospectively through repetition, as its iteration to be communicated through space and time, which ensures its transmission through history. The transcendental, or its myth, is always deferred and delayed through its communication to us with the passage of différance, this ensures that thought will always be 'to come' as the transcendental becomes re-activated from its absolute origin in the past through its repetitions in the present and future.

\section{Conclusion}

In this paper I have examined the conditions of possibility for the perpetuation of phenomenology through an account of Derrida's tracing back to the roots of metaphysics which takes différance into account, the dynamic and a priori difference between the transcendental and empirical which translates as nothing. This accounts for metaphysics' conditions of possibility and its mode of production through the concept of iterability. Iterability translates into repetition with a difference which maintains the difference between the transcendental and empirical as nothing and becomes the trace of repeatable traces which maintains the illusion that the transcendental and empirical are distinct when they are in fact, the same and interchangeable.

The supplement as the quasi-transcendental and différance, translates into that which enables the transcendental by bringing it into being as its condition of possibility, indeed philosophy becomes an infinite chain of supplements referring to each other rather than a referential signature for a transcendental signified or mythical origin. Repetition, or iterability, constitutes ideality as the transcendental is produced as separate from the empirical only through the illusion and theatrical movement of the trace. Derrida's meta-concept of différance demonstrates that the transcendentalempirical, hyle-morphe, noema-noesis distinction is an illusion and the difference which separates them is a difference which is nothing. As a 


\section{DECONSTRUCTION AND HUSSERLIAN PHENOMENOLOGY}

fundamental trace of repeatable traces it produces the transcendental and empirical through the play of differences which in effect, separate nothing. This is because the transcendental translates into the empirical, the fundamental aporia of metaphysics is that the distinction that separates the transcendental and empirical is ultimately a repetition of it as the same, or iterability.

Department of English Language and Literature, National University of Singapore, Singapore

\section{References}

Derrida, Jacques, Writing and Difference, trans. by Alan Bass (Chicago: The University of Chicago Press, 1978). , Speech and Phenomena, and Other Essays on Husserl's Theory of Signs, trans. by David B. Allison (Evanston: Northwestern University Press, 1973).

$\rightarrow$ Edmund Husserl's 'Origin of Geometry': An Introduction, trans. by John P. Leavey, Jr. (New York; Hassocks: Harvester Press; Hays, 1978).

Positions, trans. by Alan Bass (Chicago: Athlone; University of Chicago Press, 1981).

- Margins of Philosophy, trans. by Alan Bass (Brighton; Chicago: University of Chicago Press; Harvester Press, 1982).

Hegel, Georg Wilhelm Friedrich, Hegel's Preface to the Phenomenology of Spirit, trans. by Yirmiyahu Yovel (Princeton: Princeton University Press, 2005).

Husserl, Edmund, Ideas Pertaining to a Pure Phenomenology and to a Phenomenological Philosophy, First Book, trans. by F. Kersten. (Dordrecht: Kluwer, 1983). 1967).

Cartesian Meditations, trans. by D. Cairns (The Hague: Nijhoff, , The Idea of Phenomenology, trans. by Lee Hardy (Dordrecht: Kluwer, 1999).

, Thing and Space: Lectures of 1907, trans. by R. Rojcewicz (Dordrecht: Kluwer, 1997). Shorter Works, ed. by Peter Mccormick and Frederick A. Elliston (Indiana: Univesity of Notre Dame Press, 1981).

Lawlor, Leonard, Derrida and Husserl: The Basic Problem of Phenomenology (Indiana: Indiana University Press, 2002).

Mohanty, J.N., Phenomenology: Between Essentialism and Transcendental Philosophy (Evanston, Illinois: Northwestern University Press.1997). 